\title{
IMPACTOS DA SOJICULTURA DE EXPORTAÇÃO SOBRE A BIODIVERSIDADE DO CERRADO
}

\section{Impacts of the international trade of soybeans on the biodiversity of Cerrado Savannah}

Fábio Albergaria de Queiroz Doutorando em Relações Internacionais pela Universidade de Brasília Brasília/DF - Brasil fabioaq@hotmail.com

Artigo recebido para publicação em 22/12/08 e aceito para publicação em 13/07/09

RESUMO: As complexas relações entre o comércio internacional e o meio ambiente destacam-se, hoje, como um dos assuntos prioritários na agenda internacional. Muito se tem discutido a esse respeito, porém poucas são as respostas concludentes acerca dos impactos ambientais gerados pela crescente prática do livre comércio. Uma análise mais precisa sobre o assunto depende do estudo pontual de cada caso, pois as variáveis envolvidas no processo são muito complexas. Para comprovar esta assertiva, analisou-se o exemplo dos impactos do comércio internacional de soja sobre a biodiversidade do cerrado. Neste caso específico, foi possivel comprovar a existência de um vínculo direto entre o aumento dos fluxos comerciais desta commodity e o processo de perda de diversidade biológica no referido bioma.

Palavras-chave: Meio Ambiente. Livre Comércio. Soja. Biodiversidade. Cerrado.

ABSTRACT: The complex relationship between free trade and environment is, nowadays, one of the most important issues found at the international affairs agenda. Much has been discussed, but few conclusive answers on the so-called environmental impact by free trade have been drawn. An accurate analysis on the issue will depend on the individual study of each case due to its complexity. In order to verify such assumption this paper has analyzed the impacts of the international trade of soybeans on the biodiversity of Cerrado Savannah. From that specific study it has been possible to verify the existence of a direct relationship between the international trade of soybeans and the loss of biodiversity in that biome.

Keywords: Environment. Free Trade. Soybean. Biodiversity. Cerrado.

\section{INTRODUÇÃO}

Com 196.776.853 hectares, o que corresponde a aproximadamente dois milhões de $\mathrm{km}^{2}$ ou $23 \%$ do território brasileiro, o cerrado é o segundo maior bioma do Brasil sendo sua área original superada apenas pela Floresta Amazônica. A região do cerrado encontra-se distribuída, em sua maior parte, ao longo do Planalto 
Central brasileiro. Sua cobertura estende-se pelos Estados de Goiás, Tocantins, Mato Grosso, Mato Grosso do Sul, Bahia, Minas Gerais, São Paulo, Maranhão,
Piauí, Paraná, Pará e Rondônia, além do Distrito Federal (FIG. 1).

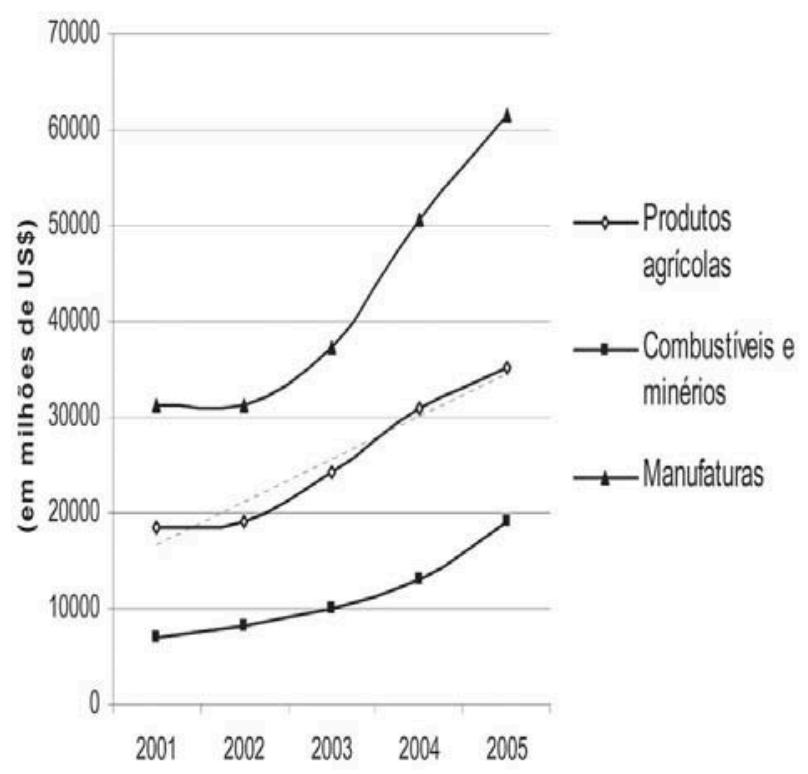

FIGURA 1. Área de abrangência do Cerrado.

Fonte: Machado et al. (2004)

De acordo com estudo desenvolvido pela WWF (2002), o Cerrado é composto por duas ecorregiões principais: a do cerrado stricto sensu e as florestas secas de Chiquitano. Este mesmo estudo também aponta para a existência de duas ecorregiões transacionais, sendo uma entre o Cerrado e a Amazônia - as florestas secas do Mato Grosso - e a outra entre o Cerrado e a Caatinga - as florestas secas do Nordeste. A descrição acima facilita o entendimento sobre a composição deste complexo bioma que possui, dentro destas ecorregiões principais, uma grande variação de ambientes como, por exemplo, formações florestais (mata ciliar, mata galeria, mata seca e cerradão), formações campestres (campo sujo, campo rupestre e campo limpo) e formações savânicas (cerrado stricto sensu, parque de cerrado, palmeiral e vereda).

Vários destes ambientes podem coexistir em uma mesma área, podendo ser encontrada uma variedade de exemplos de espécies muito ligadas a estes ambientes específicos. Estudos recentes indicam que pode ocorrer uma perda de até $25 \%$ das espécies de aves associadas com a mata de galeria apenas se houver a destruição dos ambientes naturais vizinhos à mata, mesmo que ela permaneça intocada. Isso demonstra a importância de se manter o mosaico de ambientes naturais do cerrado como estratégia básica de preservação de sua complexa e rica cadeia biológica (MACHADO et al. 2004).

O cerrado é considerado a savana de maior biodiversidade do planeta abrigando quantidade estimada entre 80.000 e 160.000 espécies, incluindo uma grande quantidade de espécies endêmicas, ou seja, nativa e exclusiva de uma única área geográfica (PORTAL BRASIL, 2004). Há bastante divergência sobre a quantidade e o nível de endemismo das espécies do cerrado, o que indica a necessidade de direcionar maiores esforços e apoio à pesquisa ambiental nesta região. 
Na TAB. 1 são apresentados dados colhidos de várias fontes sobre a biodiversidade do cerrado. Com exceção das aves, que possuem um baixo endemismo, e dos invertebrados, para os quais não foram encontradas informações, pode-se inferir que as espécies do cerrado apresentam um grau de endemismo relativamente alto, o que as expõe ao risco de completa extinção caso seu habitat natural seja destruído.

TABELA 1. Estimativa sobre a biodiversidade do Cerrado

\begin{tabular}{lccccc}
\hline & N. $^{~}{ }^{\text {ESPÉCIES }}$ & ENDÊMICAS & NÍVEL DE ENDEMISMO (\%) & BRASIL (\%) & AMEAÇADAS \\
\hline INVERTEBRADOS & 67.000 & N/D* & N/D* & 20 & N/D* \\
PLANTAS & 10.000 & 4.400 & 44 & 18 & N/D* \\
MAMÍFEROS & 199 & 45 & 22,6 & 38 & 21 \\
AVES & 837 & 45 & 5,3 & 52 & $33(14$ endêmicas) \\
ANFÍBIOS & 195 & 42 & 21,5 & 38 & 03 \\
PEIXES & 1.200 & 350 & 29 & 44 & N/D* \\
RÉPTEIS & 180 & 20 & 11 & 38 & 15 \\
\hline
\end{tabular}

Fontes: WWF/Brasil (2002); IBAMA (2004), EMBRAPA (2007)* N/D - Não Disponível

Apesar de alguns esforços de pesquisa sobre este bioma, empreendidos principalmente ao longo das décadas de 1980 e 90, há muitas incertezas quanto às estimativas numéricas acerca da biodiversidade do cerrado, o que representa uma considerável deficiência estatística e indica também a incipiente gestão ambiental por parte dos órgãos governamentais brasileiros com relação a este bioma. Dados reunidos de vários autores sugerem que, dependendo do grupo taxonômico considerado, a porcentagem de espécies que ocorrem no cerrado pode representar algo entre $20 \%$ e $50 \%$ das espécies brasileiras (MACHADO et al. 2004).

A vegetação considerada típica do cerrado, composta por árvores de pequeno porte com caules retorcidos e casca grossa, é muito bem adaptada a situações adversas como seca e fogo. Os solos são pobres em nutrientes minerais, apresentam alto grau de acidez e, por vezes, quantidades tóxicas de alumínio. Além dessas características, outros fatores como altitude, periodicidade das queimadas e declividade do solo influenciam na particular formação fisionômica deste bioma.

Esse conjunto de características tão peculiares ao cerrado, à primeira vista, conduziu à percepção equivocada de que se tratava de um bioma biologicamente pobre. No entanto, os seus estudiosos logo lançaram por terra esta crença ao denominá-lo, apropriadamente, de "floresta de cabeça para baixo". Esta denominação se deve ao fato de maior parte de sua biomassa ser subterrânea, em virtude da necessidade de desenvolver raízes profundas para a obtenção de água e nutrientes. O cerrado também ostenta o título de "berço das águas" por abrigar as nascentes de vários afluentes, parte de importantes bacias hidrográficas da América do Sul como a Amazônica, a Platina e a Bacia do São Francisco.

Esta breve introdução sobre o cerrado evidenciou tratar-se de um bioma muito peculiar que, em meio a uma fisionomia aparentemente árida e hostil, desempenha um importante papel para o funcionamento do ecossistema natural e abriga uma biodiversidade única. Esse conjunto de características singulares e sua atual situação de vulnerabilidade levaram o cerrado a ser classificado como um hotspot, isto é, como um dos 25 biomas terrestres em situação mais crítica em termos de endemismo e ameaça à suas espécies.

\section{HISTÓRICO DA OCUPAÇÃO ANTRÓPICA NO CERRADO}

A ação humana desordenada tem conduzido à ocupação predatória da região do cerrado e, conseqüentemente, à sua rápida degradação ambiental. Cer- 
ca de 78,7 \% de sua área estão sob alguma forma de uso humano, o que significa que apenas $21,3 \%$, ou $432.814 \mathrm{~km}^{2}$, ainda se conservam intactos (MITTERMEIER, 2004).

Durante a colonização do Brasil no início do século XVI, os portugueses evitavam chegar ao interior do país devido a tratados com a Espanha e a predisposições culturais e logísticas de se estabelecerem próximo ao mar. Os registros históricos relatam que primeiras incursões à procura de ouro e pedras preciosas aconteceram no século XVIII, quando a mineração desenvolveu-se rapidamente abrindo caminho para fazendas de criação de gado, principal atividade econômica até meados dos anos 50, quando o governo começou a planejar a construção de uma nova capital em Goiás para estimular a ocupação do interior brasileiro (MITTERMEIER, 2004).

Com o declínio do extrativismo mineral, o cerrado passou por um período de estagnação que durou até praticamente o início do século XX (WWF, 2000: 18-21). A ilusão de que uma nova descoberta poderia vir a qualquer momento levou muitos empresários do setor minerador a continuar destruindo lentamente seus ativos e o meio-ambiente da região, em vez de direcionar seus esforços para alguma outra atividade econômica. O sistema minerador foi desta forma se atrofiando para finalmente desagregar-se numa economia de subsistência na qual a pecuária extensiva e de baixa produtividade foi predominante (FURTADO, 2003).

Apesar do declínio da mineração, seus resultados permaneceram bem visíveis ao longo dos anos como as erosões causadas pela intensa atividade mineradora e seus impactos sobre a rede hídrica, drasticamente afetada pela utilização indiscriminada de mercúrio e pelo assoreamento dos cursos d'água. A instalação de uma malha ferroviária, na década de 1930, integrando o Centro-Oeste às principais regiões urbano-industriais do país, paralelamente ao desenvolvimento de políticas públicas voltadas para a ocupação do interior brasileiro, resultou num aumento substancial da presença e atividade humana na região do cerrado, em detrimento de uma biodiversidade até então relativamente pouco alterada.
Esse processo consolidou-se na década de 1960 com a interiorização da capital federal, inaugurada em 1964, a implantação de novas infra-estruturas viárias e a melhoria das já existentes. Um dos grandes entraves à expansão das atividades econômicas nos domínios do cerrado estava, exatamente, na falta de uma estrutura logística adequada capaz de cobrir a grande distância que separava a região dos principais pólos industriais do país, bem como dos portos por onde a produção agropecuária escoava para os mercados externos.

A oferta de uma infra-estrutura eficiente para o escoamento da produção aliada a políticas públicas que estimulavam a expansão da fronteira agropecuária - com vistas ao aumento da produção de grãos e carne voltada para a exportação - conduziu à implantação de um novo modelo produtivo, direcionado ao uso intensivo dos solos e ao desenvolvimento de grandes monoculturas. Este cenário propiciou, ao longo dos anos de 1970-80, um rápido deslocamento da fronteira agropecuária tendo como base principal a expansão de duas atividades econômicas distintas, mas inter-relacionadas: a monocultura de grãos, principalmente de soja, e a pecuária.

A pressão exercida por estas atividades sobre a fauna e flora da região, levando à conversão de áreas naturais em 'agroecossitemas', fez com que ambas fossem, enfaticamente, apontadas como as grandes ameaças à biodiversidade do cerrado (WWF, 2000).

Findo este adendo introdutório ao cerrado, será considerado na análise proposta o território compreendido pelas unidades integrantes da região Centro-Oeste (Distrito Federal, Goiás, Mato Grosso e Mato Grosso do Sul) e pelo estado do Tocantins (região norte) que, de acordo com dados atualizados do IBGE, estende-se por um total de $1.883 .988 \mathrm{~km}^{2}$. Esta região representa $94 \%$ da área original estimada do cerrado brasileiro.

Pode-se afirmar que os estabelecimentos agrícolas ocupam $67 \%$ da área total deste território, ou seja, 1,2 milhão de $\mathrm{km}^{2}$, sendo a pecuária e a sojicultura as atividades predominantes. A atividade de maior pro- 
porção em termos de área utilizada é a pecuária, estendendo-se por $60 \%$ da área ocupada por estabelecimentos agrícolas. A pecuária na região do cerrado caracteriza-se, em grande parte, por ser uma atividade de baixa tecnologia e produtividade, demandando grandes extensões de terra, mas que tende a caminhar para uma adequação às exigências dos mercados internacionais. Um grande problema dessa atividade ainda é o uso do fogo nas áreas de aproveitamento de pastos naturais. Esta prática tem sido apontada como a principal causadora das queimadas que anualmente devastam extensas áreas de mata no cerrado, principalmente durante a estação da seca, entre julho e setembro (WWF, 1999; IBGE, 1998).

Dados do WWF (2003) indicam que centenas de milhares de hectares que foram desmatados para a implementação de pastos encontram-se abandonados devido à ocupação de solos impróprios associada a técnicas inadequadas. Isso induz ao desmatamento de novas áreas apenas para a manutenção do rebanho atual.

De forma semelhante, a expansão da agricultura também tem sido apontada como uma das causas responsáveis pelo aumento substancial das taxas de desmatamento do cerrado. Fatores como a grande disponibilidade de terras, o predomínio de uma topografia plana e suavemente ondulada - favorável à agricultura mecanizada e à irrigação - e o desenvolvimento de técnicas para a correção da acidez dos solos e variedades adaptadas possibilitaram que a fronteira agrícola avançasse sobre os domínios deste bioma de uma forma extraordinariamente rápida.

Até o último censo agropecuário brasileiro, referente aos anos de 1995 e 1996, as lavouras ocupavam $6,4 \%$ da área em estabelecimentos $\left(81 \mathrm{mil} \mathrm{km}^{2}\right)$ no território foco desta análise, sendo que a maior parcela coube às lavouras anuais $\left(72 \mathrm{mil} \mathrm{km} \mathrm{km}^{2}\right.$, incluindo 8,7 mil $\mathrm{km}^{2}$ de áreas em descanso) onde se destacou a soja que vem sendo cultivada em $50 \mathrm{mil} \mathrm{km}^{2}$ (IBGE, 1998). Como será apresentado no trecho em que os impactos socioeconômicos da soja são discutidos, apesar da menor escala territorial da sojicultura quando comparada à pecuária na região do cerrado, estes dois segmentos distintos apresentam uma forte inter-relação.

O contínuo processo de degradação do cerrado, resultante da ocupação humana recente sem uma eficaz gestão sustentável dos recursos naturais por parte do Estado, faz com que este bioma, depois da mata atlântica, seja considerado o ecossistema brasileiro mais ameaçado. A ação antrópica tem sido fator determinante no processo de perda de biodiversidade do cerrado ao promover a destruição de habitats naturais essenciais à manutenção de suas espécies, desmatamento, introdução de espécies exóticas, poluição por agrotóxicos, erosão dos solos além da destruição de rios e nascentes. Ressalte-se ainda a adoção de medidas governamentais em incentivo à expansão da fronteira agropecuária no cerrado como uma possível alternativa à ocupação da Amazônia implicando, assim, tentativa de se proteger um bioma em detrimento de outro, tomado como inferior.

Procurou-se até aqui identificar as principais causas que levaram, e têm levado, à ocupação desordenada da região do cerrado e à sua conseqüente degradação. Ao longo dos próximos tópicos faz-se um estudo mais detalhado dos impactos que a expansão agrícola voltada ao comércio internacional, mais especificamente da sojicultura, tem causado sobre a economia brasileira e o cerrado.

\section{O SETOR AGRÍCOLA COMO GERADOR DE DIVISAS E DESENVOLVIMENTO ECONÔMICO: O CASO DA SOJA}

A agricultura é fator fundamental no processo de desenvolvimento econômico de qualquer país. A agricultura pode viabilizar o desenvolvimento sustentável por meio da ação governamental eficiente na formulação e implementação de políticas setoriais de desenvolvimento rural, aliadas à gestão dos recursos naturais, o que requer a devida aplicação da legislação ambiental e ordenamento territorial.

Esta contribuição da agricultura é crucial para o desenvolvimento sustentável e se dá por meio da redução da pobreza e da criação de renda no campo, 
estimulando atividades industriais correlatas, reduzindo a pressão urbana, e contribuindo para o crescimento econômico. A atividade agrícola pode contribuir para o aumento do bem-estar social ao resultar em maior geração de renda e contribuir como importante gerador de divisas, principalmente nos países em desenvolvimento, dada sua importância na composição das suas pautas de exportação (SOUZA, 1997; JOHNSTON e MELLOR, 1961).
O cumprimento destas funções permitiu a penetração do capitalismo no campo brasileiro, resultando no uso de insumos modernos e técnicas voltadas ao aumento da produção e da produtividade. Em países com forte base exportadora agrícola, como o Brasil (FIG. 2), os fatos históricos ratificam a importância das atividades desta natureza para o desenvolvimento econômico, tendo conduzido este país a figurar atualmente entre os maiores agroexportadores do planeta (TAB. 2).

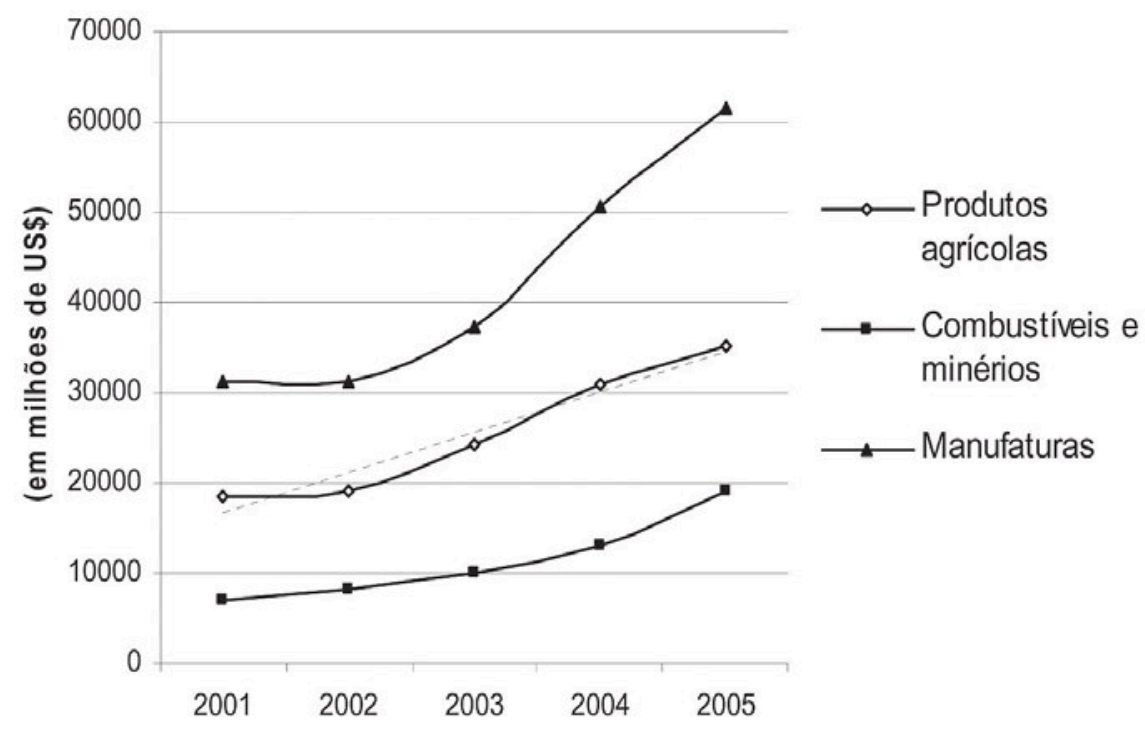

FIGURA 2. Exportações brasileiras por categoria de produtos (2001-2005)

Fonte: Organização Mundial de Comércio.

TABELA2. Principais Países Agroexportadores - 1980/2005

\begin{tabular}{lccccc}
\hline \multirow{2}{*}{ PAÍSES/ANO } & & \multicolumn{3}{c}{ Participação na produção mundial (\%) } \\
\cline { 3 - 5 } & Valor (bi US\$)2005 & 1980 & 1990 & 2000 & 2005 \\
\hline 1. União Européia & 369,71 & - & - & 41,5 & 43,4 \\
2. EUA & 82,67 & 17,0 & 14,3 & 12,9 & 9,7 \\
3. Canadá & 41,18 & 5,0 & 5,4 & 6,3 & 4,8 \\
4. Brasil & $\mathbf{3 5 , 0 4}$ & $\mathbf{3 , 4}$ & $\mathbf{2 , 4}$ & $\mathbf{2 , 8}$ & $\mathbf{4 , 1}$ \\
5. China & 28,71 & 1,5 & 2,4 & 3,0 & 3,4 \\
6. Austrália & 21,21 & 3,3 & 2,8 & 3,0 & 3,4 \\
7. Argentina & 19,18 & 1,9 & 1,8 & 2,2 & 2,3 \\
8. Tailândia & 17,82 & 1,2 & 1,9 & 2,2 & 2,1 \\
9. Rússia & 14,87 & - & - & 1,4 & 1,7 \\
10. Indonésia & 14,32 & 1,6 & 1,0 & 1,4 & 1,7 \\
11. Malásia & 13,38 & 2,0 & 1,8 & 1,4 & 1,6 \\
12. Nova Zelândia & 13,01 & 1,3 & 0,8 & 1,4 & 1,5 \\
13. México & 12,72 & 0,8 & - & 81 & 1,5 \\
TOTAL - 13 maiores & 684,27 & - & &
\end{tabular}

Fonte: Organização Mundial de Comércio. 
O fato é que desde o período colonial a agricultura tem atuado como um setor de importância estratégica para a economia brasileira. Ao longo da história a agricultura brasileira presenciou a ascensão e declínio de ciclos sucessivos de produção de commodities como a cana-de-açúcar, algodão, cacau, borracha e café, em resposta às oscilações no comportamento da demanda internacional. Mais recentemente, a partir da década de 1960, outra commodity tem se destacado como um dos principais contribuintes para o crescimento acentuado das exportações brasileiras de produtos agrícolas e derivados: trata-se da soja.

\subsection{A Sojicultura no Cerrado}

Este tópico não busca questionar os potenciais benefícios gerados pela agricultura para o crescimento econômico e melhoria da qualidade de vida de um país, mas sim identificar acontecimentos, tanto no plano nacional como internacional, que incentivaram a expansão da sojicultura no Brasil e a forma como ela aconteceu. Esta sim - a forma - é passível de questionamento quanto sua compatibilidade com o desenvolvimento sustentável.
Até o fim da década de 1970, a produção de soja no Brasil praticamente restringiu-se às regiões Sul e Sudeste (São Paulo e Minas Gerais), tradicionais produtores de grãos. Uma conjunção de fatores, domésticos e internacionais, contribuiu para que a fronteira agrícola avançasse, sobremaneira, rumo às regiões centro-oeste e nordeste, resultando na incorporação de imensas áreas de cerrado, o que culminou num extraordinário crescimento da produção brasileira de grãos, especialmente da soja.

Conforme citado anteriormente, as políticas governamentais agrícolas adotadas entre as décadas de 1960 e 1980 no Brasil buscavam incentivar, como uma de suas medidas prioritárias, a expansão da produção de commodities tendo como alvo o mercado consumidor externo, um grande atrativo dado a necessidade de gerar divisas e melhorar a balança comercial brasileira.

A elevação dos preços internacionais desta commodity levou o governo brasileiro a adotar uma política de concessão de linhas de crédito para os segmentos empresariais agrícolas que estivessem interes-

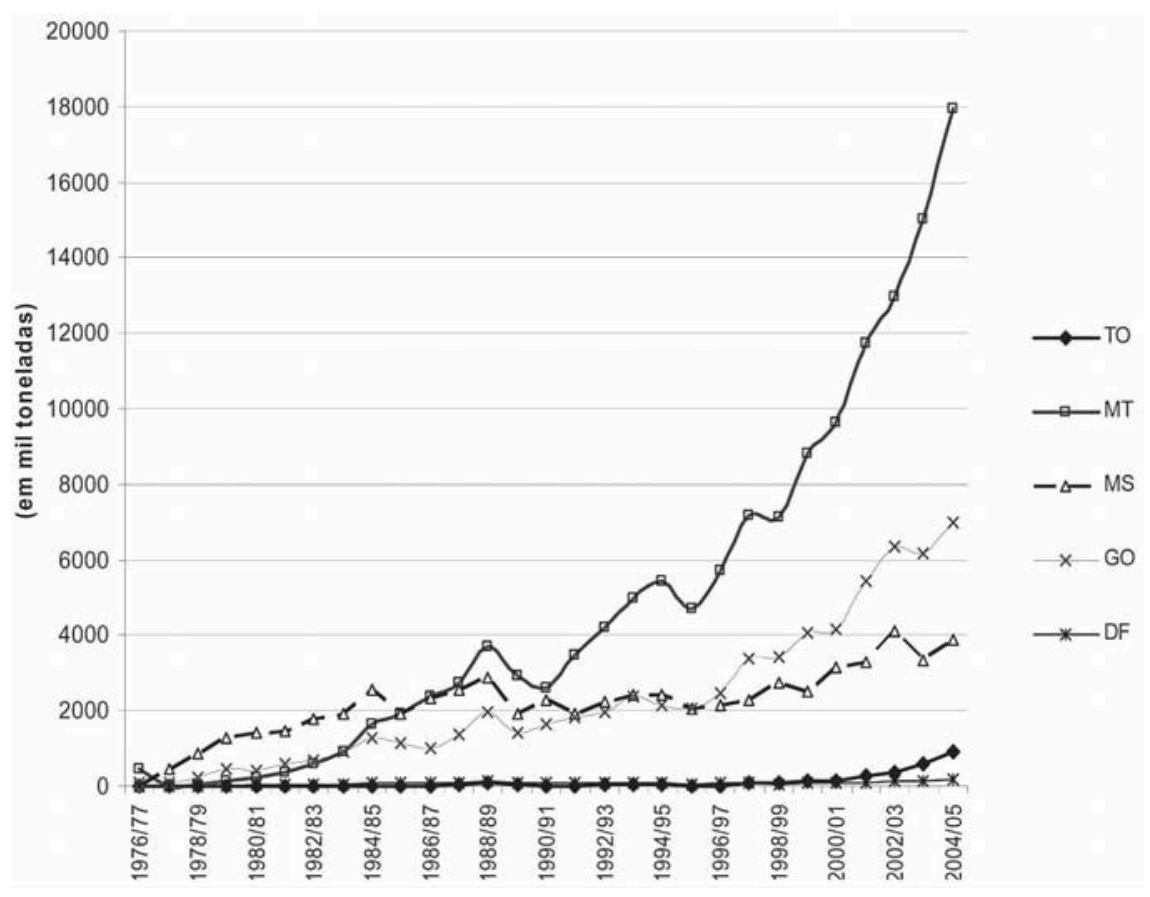

FIGURA 3. Produção de soja em estados selecionados da região do Cerrado (1976 - 2005) Fonte: CONAB 
sados na produção de soja e derivados, o que permitiu a esse país passar, em um curto período de tempo, da condição de importador a um dos maiores exportadores mundiais desta commodity.

O crescimento da produção (FIG. 3) e da área plantada de soja (FIG. 4) nos estados da região em que o cerrado é predominante (Goiás, Mato Grosso, Mato Grosso do Sul, Tocantins e Distrito Federal) é apresentado a seguir. Vale notar que três estados ocupam papel de destaque: Goiás, Mato Grosso do Sul e Mato Grosso com um crescimento bastante acentuado a partir de meados da década de 90 . Este último estado abriga uma importante fronteira com a floresta amazônica e com o pantanal, tendo figurado nas últimas décadas entre os estados brasileiros com maior nível de desmatamento. O Mato Grosso foi o estado brasileiro que mais desmatou em 2004, 2005 e 2006, de acordo com dados do Sistema Compartilhado de Informações Ambientais (SISCOM) do Ministério do Meio Ambiente/IBAMA.

Um conjunto substancial de medidas de apoio fiscal e creditício à produção agrícola brasileira foi delineado no $1^{\circ}$ Plano Nacional de Desenvolvimento (PND) vigente no período entre 1972 e 1974 (Governo Médici/1969-74). O $1^{\circ}$ PND também disponibilizou o aporte financeiro necessário à viabilização e melhoria da infra-estrutura logística da região centro-oeste, medida indispensável para o adequado escoamento de sua produção para os portos do sudeste e sul do Brasil por onde, então, a mercadoria seguia rumo ao exterior.

As características topográficas do cerrado, já citadas anteriormente, em conjunto com as referidas políticas de desenvolvimento do PND, propiciaram a extraordinária ocupação destas terras com vistas à implementação das atividades agrícolas, sobretudo da monocultura de grãos, com destaque para a soja (FIG. 4).

O processo de ocupação e exploração do cerrado intensificou-se ainda mais com o aporte científico-tecnológico disponibilizado pela EMBRAPA-Empresa Brasileira de Pesquisa Agropecuária - como as técnicas de correção da acidez dos solos e o aperfeiçoamento de variedades.

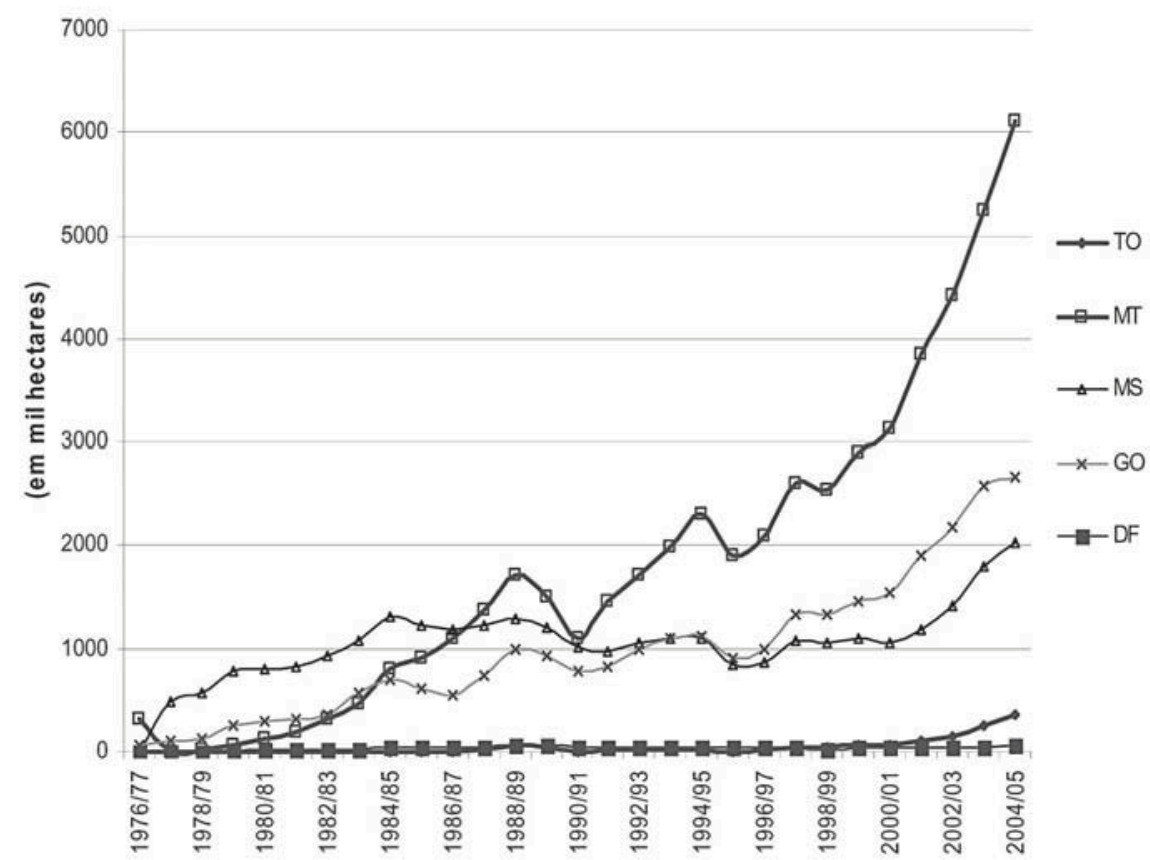

FIGURA 4. Evolução da área plantada de soja em estados selecionados da região do Cerrado (1976 - 2005)

Fonte: CONAB 
A política nacional desenvolvimentista deste período foi viabilizada por meio da captação de recursos financeiros no exterior, em sua maior parte 'petrodólares'. No entanto, com as crises do dólar (1971 e 73) e a primeira crise do petróleo (1973), a oferta internacional de crédito se modificou e a dívida externa brasileira aumentou drasticamente, uma vez que os empréstimos externos eram corrigidos por elevadas taxas de juros resultantes da instabilidade da economia internacional naquele momento. Com a segunda crise do petróleo, originada pela guerra entre o Irã e o Iraque (1979), o mundo mergulhou em um período de estagflação (inflação com recessão) que praticamente comprometeu o crescimento econômico de muitos países durante toda a década de 1980.

A recessão mundial dos anos 80 desestabilizou o comércio internacional, principalmente no caso dos produtos agrícolas que tiveram sucessivas depreciações nos seus preços devido às drásticas quedas em sua demanda, associadas à saturação do mercado de commodities.

Consequentemente, os países com forte base agrária, como o Brasil, viram a elevação de suas dívidas externas para níveis estratosféricos, grande desequilíbrio nas balanças comerciais e cortes, conforme orientações do Fundo Monetário Internacional, das linhas de créditos para incentivo à produção agrícola.

Mesmo em meio a tais adversidades, o governo brasileiro manteve os incentivos para a expansão da fronteira agrícola, pois necessitava aumentar suas exportações para gerar divisas, equilibrar sua balança comercial e fazer frente às importações do setor industrial.

Dadas estas circunstâncias, o $2^{\circ}$ PND (19751979), vigente durante o governo Geisel, traçou sua estratégia para o setor com vistas a consolidar a expansão agrícola nas áreas já ocupadas bem como financiar a incorporação de novas áreas. Visando o aumento da produtividade agrícola e competitividade de seus produtos, foram criados programas de incentivo à modernização da agricultura aliados à diversificação da pauta de exportações brasileiras.
É importante destacar uma medida que começou a ser adotada a partir de meados dos anos $1940 \mathrm{e}$ representou um forte estímulo para a ampliação da produção agropecuária no Brasil: trata-se da Política de Garantia de Preços Mínimos (PGPM). A PGPM garantiu aos produtores rurais que todo o excedente que não fosse vendido acima de um patamar pré-determinado seria comprado pelo governo brasileiro.

Além de neutralizar, pelo menos a curto e médio prazo, os efeitos da volatilidade internacional, a PGMP, aliada a outros instrumentos de política setorial agrícola como os estoques reguladores e a geração de tecnologia por instituições estatais, conseguiu manter os patamares de produção de soja nos níveis anteriores às crises externas. A PGMP passou por várias reformas desde sua criação e por um curto período de interrupção durante o processo de abertura comercial brasileira nos anos 90 , sendo aplicada atualmente à produção de soja em todo o território brasileiro (CRUZ, 2007).

A ocupação econômica do cerrado continuou sendo uma das principais alternativas para a expansão da fronteira agrícola brasileira. Vários programas foram criados para cumprir esta finalidade, dentre os quais dois se destacaram em maior medida, o POLOCENTRO (Programa de Desenvolvimento dos Cerrados) e o PRODECER (Programa de Cooperação NipoBrasileiro para o Desenvolvimento do Cerrado), descritos em maiores detalhes a seguir. Embora esses programas não tenham sido especificamente concebidos para fomentar a produção de soja, eles foram fundamentais para alavancar e movimentar forças que propiciaram notáveis incrementos na produção desta commodity na região do cerrado.

\subsection{Os programas POLOCENTRO e PRODECER I,II e III}

O programa POLOCENTRO (1975-1980) foi concebido tendo como objetivo promover o rápido desenvolvimento e a modernização das atividades agrícolas no centro-oeste brasileiro. Por meio deste programa, o governo federal buscou fortalecer a infraestrutura da região para que ela servisse ao desenvol- 
vimento da agricultura no cerrado (ALENCAR, 1975)

De acordo com ALENCAR (1975), os locais destinados a receber os benefícios do POLOCENTRO eram selecionados com base na existência de infraestrutura básica, como estradas e eletrificação rural, e na proximidade com jazidas de calcário, indispensáveis para a correção da acidez dos solos do cerrado. Seguindo esta linha de análise, as áreas eram classificadas como "prioritárias" ou "secundárias". Entre 1977 e 1979, cerca de 3,7 milhões de hectares foram beneficiados direta e indiretamente pelo programa com investimentos em rodovias, armazenagem, rede elétrica, incentivos fiscais, recursos para pesquisa agropecuária e assistência técnica.

A maior parte do crédito concedido privilegiou grandes produtores, o que conferiu ao programa, segundo os críticos, um caráter concentrador e excludente. Perto de $90 \%$ das linhas de crédito destinaram-se às propriedades com área superior a $200 \mathrm{hec}-$ tares. No total, $50 \%$ dos financiamentos foram para os produtores com propriedades acima de 2000 hectares.
Como resultado, o POLOCENTRO viabilizou a incorporação efetiva de quase 2,5 milhões de hectares à agricultura e à pecuária. No caso específico da soja, a área cultivada passou de 82.000 hectares em 1975 para 520.000 hectares em 1980 (WARNKEN, 1999). O POLOCENTRO foi substituído pelo modelo agro-industrial cooperativo do PRODECER, implementado em três fases, destinado a promover a ocupação das áreas do cerrado, dando assim, continuidade aos programas que consubstanciaram o seu antecessor.

Os programas PRODECER I, II e III foram viabilizados pela ação conjunta empreendida entre entidades públicas e privadas brasileiras e a Agência Japonesa para a Cooperação Internacional: a JICA (Japanese International Cooperation Agency). Sendo o Japão um grande importador de produtos agrícolas (TAB. 3), o crescimento da produção brasileira de soja para exportação atendia seus interesses por conduzir à redução do nível de preços internacionais desta commodity e da capacidade de influência que até então desfrutavam seus maiores produtores no mercado internacional.

TABELA 3. Principais exportadores e importadores de soja em grãos -2004

\begin{tabular}{lcc|lcc}
\hline $\begin{array}{l}\text { Principais exportadores } \\
\text { de Soja }\end{array}$ & $\begin{array}{c}\text { Valor } \\
\text { (mil US\$)2004 }\end{array}$ & $\begin{array}{c}\text { Participação no } \\
\text { total mundial (\%) }\end{array}$ & $\begin{array}{l}\text { Principais importadores } \\
\text { de Soja }\end{array}$ & $\begin{array}{c}\text { Valor } \\
\text { (mil US\$)2004 }\end{array}$ & $\begin{array}{c}\text { Participação no } \\
\text { total mundial (\%) }\end{array}$ \\
\hline 1.EUA & 6.692 .044 & 42,9 & $\mathbf{1 . C H I N A}$ & 7.695 .178 & 39,2 \\
2. BRASIL & $\mathbf{5 . 3 9 4 . 9 0 7}$ & $\mathbf{3 4 , 6}$ & $\mathbf{2 . J A P A ̃ O}$ & 1.774 .624 & 9,0 \\
3.ARGENTINA & 1.740 .114 & 11,1 & $\mathbf{3 . H O L A N D A}$ & 1.504 .202 & 7,7 \\
4.PARAGUAI & 578.705 & 3,7 & 4.ALEMANHA & 1.129 .566 & 5,7 \\
5. HOLANDA & 489.140 & 3,1 & $\mathbf{5 . M E ́ X I C O}$ & 1.107 .989 & 5,6 \\
6.CANADÁ & 295.300 & 1,8 & $\mathbf{6 . E S P A N H A}$ & 780.739 & 3,9 \\
7.CHINA & 150.034 & 0,9 & 7.ITÁLIA & 481.238 & 2,45 \\
8.URUGUAI & 82.662 & 0,5 & $\mathbf{8 . C O R E ́ I A D O S U L ~}$ & 480.300 & 2,4 \\
TOTAL- 08 maiores & $\mathbf{1 5 . 4 2 2 . 9 0 6}$ & $\mathbf{9 8 , 6 \%}$ & TOTAL- 08 maiores & $\mathbf{1 4 . 9 5 3 . 8 3 6}$ & $\mathbf{7 5 , 9 5 \%}$ \\
\hline
\end{tabular}

Fonte: FAO Statistical Yearbooks 2005/2006.

Disponível em: $<$ http://www.fao.org/statistics/yearbook/vol_1_1/xls/c18. xls $>$

O PRODECER I (1979), estabelecido no oeste de Minas Gerais, incorporou ao sistema produtivo nacional cerca de 70.000 hectares de terras do cerrado por intermédio de programas de crédito baseados em cooperativas. O PRODECER II (1985), mais amplo, estendeu seus projetos de ocupação aos estados do
Mato Grosso, Mato Grosso do Sul, Goiás e Bahia superando os 200.000 hectares de terra. Em sua terceira versão, estabelecida em 1993, o programa contemplou as regiões Norte e Nordeste, mais especificamente os estados do Maranhão e Tocantins, respondendo pela ocupação de 40.000 hectares em cada um dos 
projetos (OSADA, 1999; WARNKEN, 1999).

Embora seus resultados tenham sido mais modestos se comparados com o POLOCENTRO, os programas do PRODECER estimularam a migração de milhares de agricultores para a região do cerrado, o que culminou com a ocupação de mais de 300.000 hectares e contribuiu para o acentuado crescimento do número de habitantes da região do cerrado (FIG. 5).

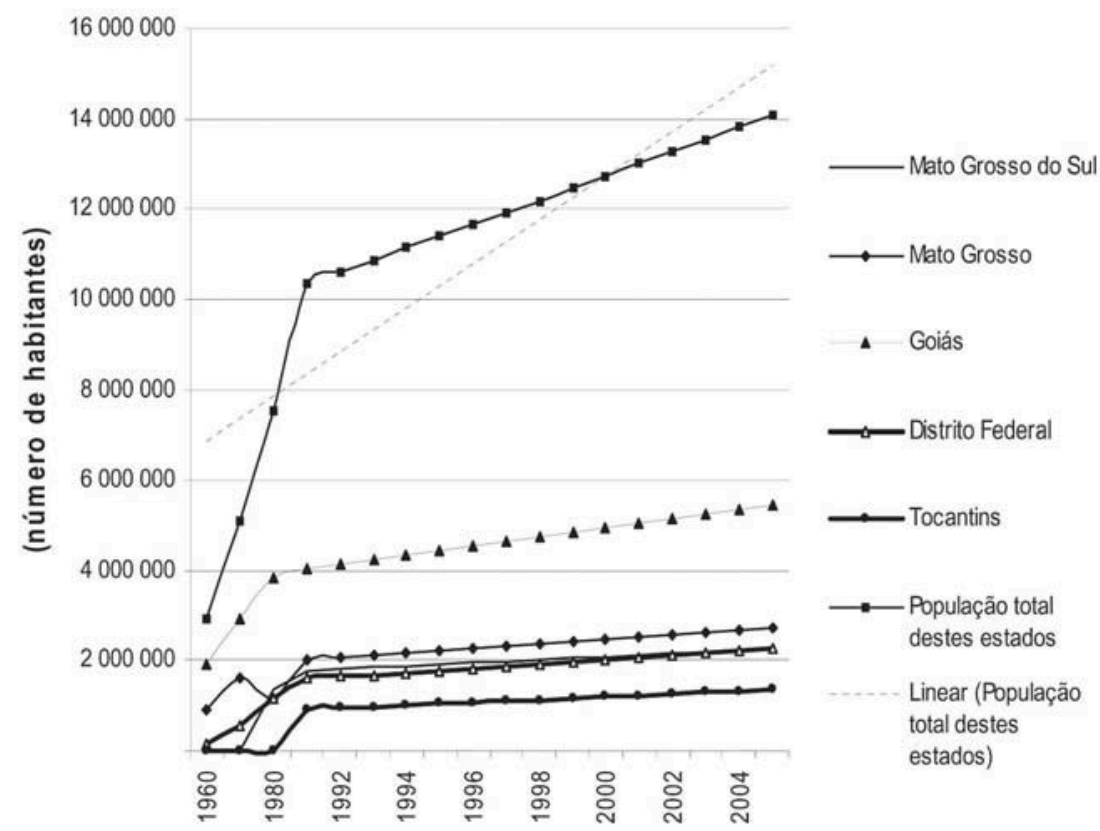

FIGURA 5. Número de habitantes em estados selecionados da região do Cerrado (1960-2005) Fonte: IBGE (2007)

Segundo dados da organização CAMPO, criada em 1978 para implantar o PRODECER, o montante gasto durante as três fases do programa alcançou a cifra de US\$ 570 milhões. Desta forma, uma área aproximada de 350.000 hectares de cerrado nos estados de
Minas Gerais, Goiás, Bahia, Mato Grosso, Mato Grosso do Sul, Maranhão e Tocantins foi ocupada com a finalidade de desenvolver atividades agropecuárias, conforme ilustrado na TAB. 4.

TABELA 4. Aplicação e Resultados do PRODECER nos estados beneficiados

\begin{tabular}{|c|c|c|c|c|}
\hline Estado & Projetos & Área Total & Investimento (US\$) & Observações \\
\hline Minas Gerais & 11 Projetos +3 empresas & $151.250 \mathrm{ha}$ & 239.000 .000 & P-I, P-II/P, P-II/E \\
\hline M. Grosso Sul & 01 projeto & 22.000 ha & 26.000 .000 & P-II/E \\
\hline Mato Grosso & 02 projetos & 35.320 ha & 50.000 .000 & $\mathrm{P}-\mathrm{II} / \mathrm{P}$ \\
\hline Goiás & 03 projetos & 30.000 ha & 50.000 .000 & P-II/E \\
\hline Bahia & 02 projetos & $31.430 \mathrm{ha}$ & 67.000 .000 & $\mathrm{P}-\mathrm{II} / \mathrm{P}$ \\
\hline Tocantins & 01 projeto & 40.000 ha & 69.000 .000 & P-III/P \\
\hline Maranhão & 01 projeto & 40.000 ha & 69.000 .000 & $\mathrm{P}-\mathrm{III} / \mathrm{P}$ \\
\hline Total & 21 projetos & 350.000 ha & 570.000 .000 & \\
\hline
\end{tabular}

Legenda: $\mathbf{P}-\mathbf{I}=$ Prodecer - I; P-II/P = Prodecer II - Piloto; P-II/E = Prodecer II - Expansão; P-III/P = Prodecer III - Piloto

Fonte: $<$ http://www.ada.com.br/campo/prodecer.htm $>$ 


\section{RESULTADOS DA EXPANSÃO DA SOJICUL- TURA PARAA ECONOMIA BRASILEIRA}

Os fatos até aqui relatados são apenas alguns dos principais acontecimentos que culminaram num processo maciço de ocupação do cerrado e, consequentemente, implementação e expansão da monocultura de soja que se tornou um dos principais produtos de exportação e captação de divisas estrangeiras para o Brasil.

A soja atua como um grande potencializador das economias locais e regionais envolvendo atividades complementares que vão desde o fornecimento de máquinas, insumos e assistência técnica, à logística de comercialização e transportes. Adicionalmente, a necessidade de rotação de culturas acaba gerando outros produtos que também dinamizam setores diversos. Esse é o caso do milho que estimula os segmentos da pecuária que dependem de ração como a suinocultura e a avicultura, que, por sua vez, vão impulsionar a indústria frigorífica em plantas integradas que industrializam a carne, fabricam a ração e o adubo e trabalham com o sistema de parceria na engorda dos animais (WWF, 1999).

De uma forma geral, a produção da soja é considerada atualmente como uma atividade desempenhada por grandes produtores, em razão de ser em boa parte negociada no mercado internacional, onde o acesso à informação, a produção em escala, o uso intensivo de tecnologia, o ganho contínuo de produtividade e o suporte financeiro para lidar com eventuais oscilações são pré-requisitos (WWF, 1999). Devido a seu alto grau de mecanização, a cultura da soja em grande escala tem sido criticada por não gerar um impacto substancial em termos de números de empregos diretos criados. De acordo com estudo da WWF, para cada 170 a 200 hectares de plantio, em média, somente um trabalhador é necessário sendo este geralmente submetido a contratos em regimes sazonais e com baixa remuneração. (WWF, 2000; WWF, 2002).

O êxito financeiro da cultura de grãos na região do cerrado, principalmente de soja, tem levado o governo e o setor privado a discutir conjuntamente um plano de implantação de corredores de exportação com a finalidade de melhorar o escoamento produtivo por meio da reestruturação do sistema logístico da região. Estes investimentos gerarão maiores incentivos não apenas para as lavouras já instaladas, mas também para a introdução de novas plantações e atividades complementares e interrelacionadas, incluindo a pecuária.

Indubitavelmente, a sojicultura possibilitou ao Brasil destacar-se no cenário internacional como um dos principais agroexportadores do planeta. A expansão da cultura de soja se deu de maneira impressionante, o que colocou este país em posição de destaque entre os maiores produtores mundiais desta commodity e de seus derivados.

\section{IMPACTOS DO COMÉRCIO INTERNACIONAL DE SOJA NA BIODIVERSIDADE DO CERRADO}

A análise apresentada no tópico anterior ressaltou a dimensão e a importância da agricultura, em especial da sojicultura, para a economia brasileira e particularmente para a região centro-oeste, onde se encontra a maior parte do bioma cerrado. Os fatos e dados analisados levam à conclusão de que a soja é um dos mais importantes produtos brasileiros em termos de geração de divisas, caracterizando-se essencialmente como uma monocultura de exportação. Tendo em conta estes fatores, daremos continuidade ao objetivo principal deste artigo que consiste em discutir os impactos diretos e indiretos do comércio international e da produção de soja sobre a biodiversidade do cerrado.

Dado o que foi exposto até o momento, observou-se que as políticas desenvolvimentistas adotadas no país, principalmente a partir da década de 1960 , viabilizaram no cerrado a construção de um modelo produtivo que primou pela expansão da fronteira agrícola e da produção voltada para a exportação. Adversamente aos bons resultados obtidos financeiramente, este modelo agroexportador impõe custos ambientais consideráveis num processo contínuo de degradação do cerrado que, em termos de biodiversidade, é um dos biomas mais ricos do planeta. Em estudo da WWF (2002) as estimativas indicam que o crescimento da 
produção de soja brasileira, impulsionada pela crescente demanda da China e da União Européia, pode levar ao desmatamento de um área de $220 \mathrm{mil} \mathrm{km}{ }^{2}$ (equivalente à Grã-Bretanha) num prazo de cerca de 15 anos.

Este aspecto é agravado pela tendência mundial e forte apelo político de disseminar o uso dos chamados bicombustíveis (biodiesel e etanol). $\mathrm{O}$ aumento da demanda internacional por biodiesel e etanol tende a estimular a ampliação da fronteira agrícola e da monocultura para o suprimento da matéria-prima necessária à sua produção (oleaginosas e cana-de-açúcar), com significante risco de impacto para o ecossistema natural (PROCÓPIO, 2007).

Como já discutido anteriormente, prevalece entre os especialistas da área a percepção de que a monocultura intensiva de grãos, principalmente de soja, é atualmente uma das principais ameaças à bio-diversidade do cerrado, sendo responsável pela conversão de extensas áreas naturais em sistemas agrícolas. Direta e indiretamente, a monocultura de grãos e a pecuária extensiva também provocam impactos consideráveis em outros biomas que fazem fronteira com o cerrado como a floresta amazônica, o pantanal e a caatinga.

A geração de externalidades ambientais como a erosão e perda de solos férteis; o comprometimento dos recursos hídricos e edáficos; desmatamento; destruição de habitats naturais; aumento do risco e aceleração do processo de desertificação e alteração dos regimes naturais da região, devido a uma série de fatores diretamente associados à produção de soja, como a expansão da pecuária e setores complementares, a forte utilização de insumos químicos, mecanização intensiva, necessidade de extensas áreas para o seu cultivo, sistema de irrigação, conduz à conclusão de que a sojicultura tem atuado como um dos grandes agentes no processo de perda de biodiversidade do cerrado.

Portanto, a inadequada consideração dos custos ambientais gerados pela expansão da sojicultura bem como a falta de uma gestão pública dos recursos naturais e ineficaz implementação da legislação am- biental (reservas legais - áreas mínimas de proteção ambiental por propriedade, respeito a mananciais e matas ciliares, por exemplo) nos levam ao questionamento do modelo de desenvolvimento rural implantado no cerrado, tendo em consideração sua compatibilidade com os princípios do desenvolvimento sustentável.

Vários problemas têm sido apontados como exemplos que corroboram a assertiva acima, um deles é a questão hídrica. As importantes bacias hidrográficas localizadas nos domínios do cerrado correm grandes riscos devido a mudanças no regime natural das águas e à escassez provocada pela substituição da vegetação nativa e pela irrigação intensiva que altera o regime de dispersão e acumulação hídrica, resultando em assoreamento e poluição dos mananciais (WWF, 2000).

A agricultura utiliza uma grande parte dos recursos hídricos em sua produção, muitas vezes sem a preocupação de otimizar o seu uso, visto o custo reduzido da água no meio rural. De acordo com a agência das Nações Unidas para Alimentação e Agricultura (FAO), a agricultura no Brasil utiliza cerca de $62 \%$ da água consumida no país, superando em larga escala o setor industrial (18\%) e o uso doméstico $(20 \%)$.

Verifica-se que o processo de degradação ambiental desencadeado pelo modelo agroexportador da soja, em conjunto com a pecuária, exerce uma grande pressão sobre a diversidade biológica do cerrado, colocando em risco a sobrevivência de diversas espécies de sua flora e fauna, já que boa parcela desta biodiversidade é endêmica e dependente da regularidade dos regimes naturais para a sua existência.

Viu-se anteriormente que a cultura de soja e a pecuária demandam um complexo sistema de infraestrutura para o adequado escoamento de sua produção. Nesse sentido, teme-se que a ampliação do sistema logístico por meio da abertura de novas estradas, ferrovias e hidrovias, possibilitada pela implantação dos corredores de exportação, possa estimular a ocupação territorial desordenada, ameaçar as poucas áreas de cerrado ainda preservadas e, conseqüentemente, a riqueza biológica desta região e o funcionamento do ecossistema. 
Tal temor se traduz, por exemplo, na possibilidade de invasão de terras, urbanização precária sem o planejamento e a fiscalização governamental adequados, ampliação da pecuária extensiva, desenvolvimento predatório de atividades complementares à cultura da soja e à pecuária, modificação dos canais hídricos e dragagem (no caso das hidrovias), destruição de habitats naturais decorrente da ocupação desordenada e débil governança ambiental (PROCÓPIO, 2007).

Destarte, considerando: a) a acentuada ampliação da área plantada de soja no cerrado bem como os impactos diretos e indiretos gerados por este processo, b) os sucessivos recordes de desmatamento dos principais estados produtores de soja nesta região, e c) a forte relação entre as espécies da flora e fauna do cerrado e seus habitats naturais, o que é especialmente importante quando levamos em consideração a quantidade de espécies endêmicas e a pouca superfície ain- da remanescente, verifica-se uma relação expressiva entre a expansão da sojicultura e o processo de perda de biodiversidade no cerrado.

De acordo com dados da Organização Mundial do Comércio e da FAO, previamente apresentados nas TAB. 2 e 3, apenas a exportação de soja em grãos representou cerca de 15 por certo do total das agroexportações brasileiras em 2005, o que não inclui a participação dos produtos derivados da soja como o óleo e o farelo, também comercializados em grande escala. Desta forma, dada a crescente importância da região do cerrado para o total da produção brasileira de soja (FIG. 6), assim como a forte participação deste item na pauta de exportações, as perspectivas indicam que os esforços governamentais voltados para financiar e maximizar a produção desta commodity e de seus derivados serão mantidos.

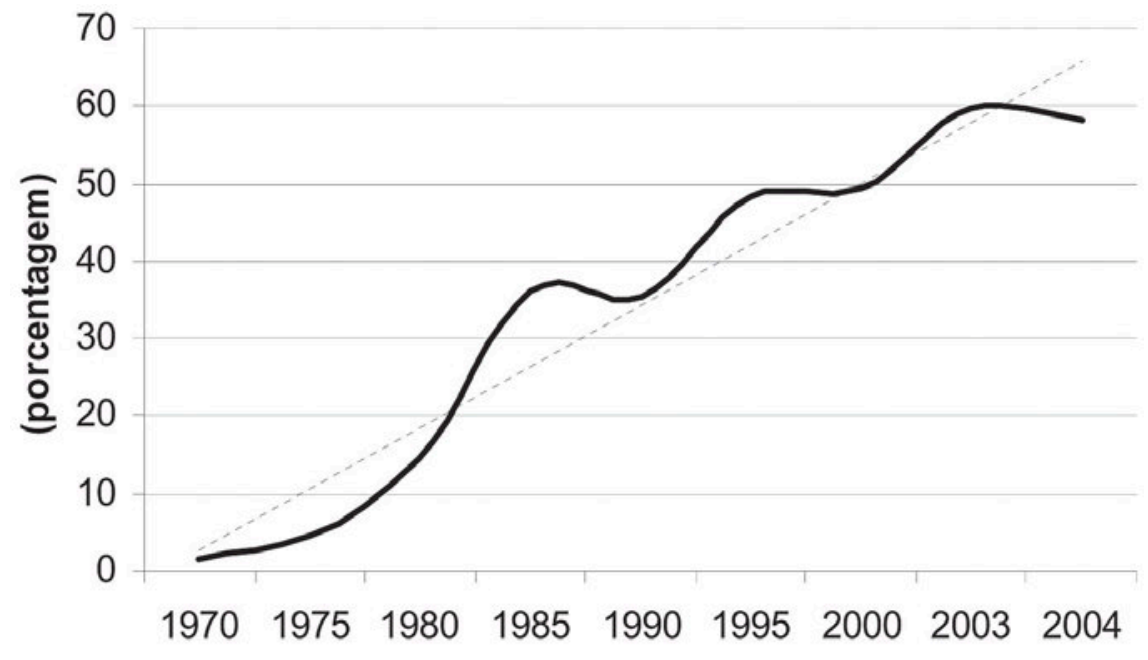

FIGURA 6. Contribuição relativa da região do cerrado para a produção brasileira de soja Fonte: IBGE, CONAB, CNA.

A grande crítica que se faz é que as estratégias de ocupação progressiva da região centro-oeste e da expansão da sojicultura, possibilitadas em boa parte pelos programas governamentais (PNDs, POLO-CENTRO, PRODECER, etc.), não demonstraram ter levado em consideração a possibilidade iminente de destruição do bioma cerrado, tampouco se pautaram em uma gestão sustentável dos recursos naturais por meio da implementação de áreas prioritárias para a conservação deste bioma, do monitoramento e ampla publicidade da situação de sua biodiversidade, nem de medidas eficazes para conter os evidentes impactos adversos sobre o ecossistema da região. 
Desta forma, em um cenário nacional e internacional propício à concessão de incentivos para a expansão agropecuária, estima-se que no curto e médio prazo as áreas do cerrado que ainda encontram-se relativamente preservadas possam vir a ser rapidamente ocupadas por monoculturas ou por atividades interrelacionadas. Ressalte-se que, de maneira alguma, postula-se aqui contra o desenvolvimento econômico que é vital para qualquer país. No entanto, o seu comprometimento com a sustentabilidade faz-se fundamental por se tratar, no caso proposto, de uma das biodiversidades mais ricas do planeta, um bioma com grande potencial de ser utilizado de forma sustentável e produzir insumos com alto valor agregado garantindo, assim, sua exploração racional e a certeza de que as gerações futuras terão acesso a uma riqueza natural imensurável.

\section{A CONSTRUÇÃO DA SUSTENTABILIDADE NO CERRADO}

Para o estudo de caso em questão, foi possível inferir haver um vínculo direto entre o processo de perda de biodiversidade no cerrado e a expansão da fronteira agrícola com vistas à produção de commodities para exportação, onde a soja destaca-se como produto principal.

Dentre os principais fatores apontados como responsáveis pela expansão da sojicultura na região do cerrado estão: as políticas governamentais de incentivo à produção de commodities para exportação; a necessidade de o país gerar divisas para equilibrar sua balança de pagamentos; o aumento da demanda mundial pela soja e seus derivados; as características topográficas do cerrado propícias ao desenvolvimento deste tipo de atividade; a ausência de consideração sobre as externalidades ambientais bem como de medidas ambientais preventivas, mitigadoras, repressivas e punitivas; a percepção prevalecente nacional e internacionalmente, inclusive nas populações locais, de que o cerrado é um bioma de menor importância, biologicamente pobre e, portanto, destinado à ocupação das culturas de grãos e da pecuária.

Esse conjunto de fatores conduz à conclusão de que a expansão da sojicultura e das atividades complementares a ela têm gerado significantes externalidades ambientais como desmatamento; destruição de habitats; erosão dos solos; aumento do risco e aceleração do processo de desertificação; contaminação dos mananciais pelo uso excessivo de agrotóxicos; e alteração dos regimes naturais essenciais à manutenção da vida neste bioma que, no todo, tem resultado em perda ou iminente risco de extinção de boa parte de sua biodiversidade. Logo, a expansão da sojicultura para exportação foi e continua sendo uma das grandes ameaças à preservação da diversidade biológica do cerrado.

Também foi possível observar que as tendências analisadas sinalizam que, dada a dimensão e importância da soja para a economia brasileira, os esforços governamentais voltados para financiar e maximizar a produção desta commodity e de seus derivados serão mantidos, o que poderá promover o avanço da fronteira agrícola sobre o que ainda resta do cerrado. Um claro sinal nesta direção é a ausência do cerrado entre os biomas resguardados pela Constituição Federal Brasileira. Gozam desta proteção a Floresta Amazônica brasileira, a Mata Atlântica, a Serra do Mar, o Pantanal Mato-Grossense e a Zona Costeira (CF/1988, art. $225, \S 4^{\circ}$ ). Conforme se constatou por meio da análise empreendida, o que há muito se vê é o incentivo à exploração intensiva do cerrado por meio de iniciativas governamentais.

Uma importante medida para a conservação deste bioma está na ampliação da capacidade estatal de implementação da legislação ambiental, gestão dos recursos naturais e criação de novas Unidades de Conservação (UCs) e corredores ecológicos que contemplem a preservação das áreas de cerrado ainda nativas e de sua biodiversidade. Essa assertiva encontra amparo na Agenda 21 Brasileira (2002) que afirma serem as UCs importantes instrumentos para a conservação da biodiversidade. Esta necessidade torna-se ainda mais premente uma vez que o cerrado é o bioma brasileiro mais desprotegido em termos de Unidades de Conservação.

Adicionalmente, recursos complementares para a pesquisa sócio-ambiental, catalogação de espécies e 
monitoramento estatístico sistemático da biodiversidade fazem-se essenciais para possibilitar uma gestão sustentável do bioma cerrado. A disponibilidade de informações e acesso público a séries temporais sobre a situação da biodiversidade do cerrado é fundamental para a avaliação do desempenho dos órgãos públicos na sua gestão. Estes são campos particularmente interessantes para o direcionamento de esforços provenientes da cooperação internacional que, desta forma, poderiam contribuir para uma melhor transparência pública e governança ambiental no Brasil.

\section{REFERÊNCIAS}

ALENCAR, G. "O POLOCENTRO no Contexto do II PND”. In: O II PND e os Programas de Desenvolvimento do Distrito Federal e do Centro-Oeste. Estudos e Debates I. Brasília: Senado Federal, Comissão de Assuntos Regionais, 14 de Maio de 1975.

BRASIL. Constituição da República Federativa do Brasil de 1988. 13. ed. Brasília: Câmara dos Deputados, 2000.

COMPANHIA NACIONAL DE ABASTECIMENTO - CONAB. Conjuntura Anual - Soja/2002. Disponível em $<$ http://www.conab.gov.br $>$. Acesso em fev. 2003, p. 98-105.

Séries históricas - Soja, Brasília, 2007.

CONFEDERAÇÃO DA AGRICULTURA E PECUÁRIA NO BRASIL - CNA. Área e Produção de Soja no Cerrado. Brasília, 2007.

CRUZ, K. As intervenções públicas de apoio à comercialização do algodão em pluma brasileiro na safra 2005/06. In: XV CONGRESSO DA SOCIEDADE BRASILEIRADE ECONOMIA, ADMINISTRAÇÃO E SOCIOLOGIA RURAL, 22-25/Jul./2007. Londrina. Anais... Londrina: UEL, 2007.

EMPRESA BRASILEIRA DE PESQUISA AGROPECUÁRIA - EMBRAPA. Biodiversidade do Bioma Cerrado. Brasília, 2007.
FOOD AND AGRICULTURE ORGANIZATION FAO. Statistical Yearbooks 2005/2006. Rome, 2006.

. Aquastat - Information System on Water and Agriculture. Country Profiles, Rome, 2007.

FURTADO, C. Formação Econômica do Brasil. São Paulo: Companhia Editora Nacional, 2003.

INSTITUTO BRASILEIRO DO MEIO AMBIENTE E DOS RECURSOS NATURAIS RENOVÁVEIS IBAMA. Ecossistemas Brasileiros: Projetos de Conservação e Manejo de Ecossistemas. 2004. Disponível em $<$ http://www.ibama.gov.br $>$. Acesso em dez. 2004.

Sistema Compartilhado de Informações Ambientais, Brasília, 2007.

INSTITUTO BRASILEIRO DE GEOGRAFIA E ESTATÍSTICA-IBGE. Censo agropecuário 1995-1996, n.1: Brasil. Rio de Janeiro, 1998.

. Indicadores de Desenvolvimento Sustentável. 2002. Disponível em <http://www.ibge.gov.br $>$. Acesso em jun. 2002.

. Estimativas Populacionais. Brasília, 2007.

JOHNSTON, B.; MELLOR, J. W. El Papel de la Agricultura en el Desarollo Económico. El Trimestre Económico, $1^{\circ}$ trimestre, México, 1961.

MACHADO, R. et al. Estimativas de perda da área do Cerrado brasileiro, Conservation International, Brasília, 2004.

MINISTÉRIO DA AGRICULTURA. Agricultura Mundial. Brasília, 2004. Disponível em <http:// www.agricultura.gov.br>. Acesso em out. 2004.

MINISTÉRIO DO MEIO AMBIENTE. Agenda 21 Brasileira: Resultado da Consulta Nacional. Brasília: MMA/PNUD, 2002.

MITTERMEIER, R. et al. Hotspots Revisited: Earth's 
Biologically Richest and Most Endangered Terrestrial Ecoregions. Chicago: The University of Chicago Press, 2004.

OSADA, N. PRODECER: Projetos no cerrado e dívidas agrícolas. Carta Asiática, São Paulo: Universidade de São Paulo, 1999.

PORTAL BRASIL. Características do Cerrado. 2004.

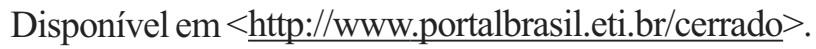
Acesso em dez. 2004.

PROCÓPIO, A. Subdesenvolvimento Sustentável. Curitiba: Juruá, 2007.

SOUZA, N. de J. Desenvolvimento Econômico. 3. ed. São Paulo: Atlas, 1997.

WARNKEN, P. O Setor da Soja no Brasil. Revista de Política Agrícola. São Paulo, n. 2, ano VII, abril/jun. 1999. Disponível em < http://www.agricultura.gov.br/ spa $>$. Acesso em fev. 2003.

WORLD TRADE ORGANIZATION - WTO. Statistics Database. Geneva, 2007.

WORLD WILDLIFE FUND - WWF. Repercussões Ambientais da Expansão da Soja no Cerrado e seus Vinculos com a Liberalização do Comércio e a Politica Macroeconômica Brasileira. Brasília: WWF Brasil, 1999.

. Expansão Agrícola e Perda da Diversidade no Cerrado: Origens Históricas e o Papel do Comércio Internacional. Brasília: WWF Brasil, 2000.

O Cerrado. 2002. Disponível em $<\underline{\mathrm{http}} / / /$ www.wwf.org.br>. Acesso em dez. 2004.

. Soja. 2003. Disponível em $<\underline{\text { http:// }}$ www.wwf.org.br>. Acesso em dez. 2004. 